\title{
Computational Framework for Port Community Systems Towards Synchromodal Freight Networks
}

\author{
João lemos nabais a , Carlos Batista a, Miguel Ayala Botto b, \\ ENCARNACIÓN CORDÓN LAGARES ${ }^{c}$
}

a Polytechnic Institute of Setúbal, School of Business Administration, Campus do IPS, Estefanilha, 2914-503 Setúbal, Portugal.E-mail: joao.nabais@esce.ips.pt, carlos.batista@esce.ips.pt

b Universidade de Lisboa, Instituto Superior Técnico,Campus Alameda, 1049-001 Lisboa, Portugal. E-mail: ayalabotto@tecnico.ulisboa.pt

c Universidad de Huelva, Facultad de Ciencias Empresariales y Turismo, Campus de la Merced, Plaza de la Merced, s/n, 21002 Huelva, España.E-mail: ecordon@uhu.es

\begin{abstract}
Port Community Systems (PCS) plays a role in supporting the competitiveness and efficiency of seaports through the reduction in both costs and the time needed for cargo to stay at the port. At seaports, multiple transport providers interact and a transport modal switch may occur. Seaports are therefore especially suited to assist the collaboration between terminals and transport providers. For doing so, a framework for sharing information between partners is needed in order to find transport solutions that can deliver cargo on-time, in a typical win-win situation. In this paper, we discuss a framework for guiding a wise allocation of cargo. The seaport is modeled as a store system, and cargo is categorized according to fixed properties and time varying properties (remaining time until due-time or expiration date). The cooperation is done in real-time and is a step towards synchromodal freight networks.
\end{abstract}

Keywords: Freight networks, Information Systems, Cooperation, Seaports.

\section{Marco computacional para los sistemas comunitarios portuarios hacia redes de transporte de mercancías sincromodal}

\section{RESUMEN}

Los Sistemas Comunitarios de Puertos (SCP) desempeñan un papel de apoyo a la competitividad y la eficiencia de los puertos a través de la reducción tanto de los costes operativos como del tiempo necesario que tienen que permanecer los buques en el puerto. En los puertos, múltiples proveedores de transporte interactúan y pueden ocurrir cambios en los modos de transporte. Por lo tanto, los puertos son especialmente adecuados para ayudar a la colaboración entre las terminales y los proveedores de transporte. Para ello, se necesita un marco para compartir información entre los colaboradores a fin de encontrar soluciones de transporte para que puedan entregar la carga a tiempo, en una situación típica en la que todos salen ganando. En este documento, se presenta un marco que sirva de orientación para una adecuada asignación de la carga. El puerto marítimo se modela como un sistema de almacenamiento, y la carga se clasifica de acuerdo con propiedades fijas y propiedades variables en el tiempo (tiempo restante hasta el plazo señalado o la fecha de vencimiento). La cooperación se realiza en tiempo real y es un paso hacia las redes de transporte de mercancías sincromodal.

Palabras Clave: Redes de transporte de mercancías, Sistemas informáticos, Cooperación, Puertos marítimos.

Clasificación JEL: E17, R41

\footnotetext{
${ }^{*}$ This work was supported by FCT, through IDMEC, under LAETA Pest-OE/EME/LA0022
}

Artículo recibido en julio de 2018 y aceptado en septiembre de 2018

Artículo disponible en versión electrónica en la página www.revista-eea.net, ref. ə-36310 


\section{INTRODUCTION}

Seaports are part of freight transportation networks whose main objective is to deliver cargo at the agreed time, at the agreed location, and in the agreed conditions (Stahlbock and Voß, 2008; Carlo et al., 2014). At seaports, multiple actors are present forming a complex network (Port Community System - PCS). Coordination between these actors plays a vital role supporting the competitiveness and efficiency of the port leading to a reduction of costs and the time needed for cargo to stay in the port. The relations within the PCS are based on one or more of the following dimensions: physical, financial and information flows. The information flow is critical to support planning, execution, managing and reporting in particular for container handling (van Oosterhout, 2008). The Port Authority holds an important role as initiator and creator of the port development strategy and coordination of the entire Port Community. The terminals present at the seaport are responsible for the physical handling of goods (physical flow) acting as intermediates between the land and maritime transport.

The PCS is an open electronic platform that has the capability to connect multiple systems operated by the different seaport organizations (Rondon and Ramis-Pujol, 2006). The PCS enables intelligent and secure exchange of information between both private and public organizations, with the aim to improve competitiveness of the port. PCS is a way to foster the cooperation among all organizations, which is necessary for the optimization of the logistics processes leading to a single data submission, usually referred as Single Window. The development of PCS can be categorized in different phases (Langen and Lugt, 2017). At the beginning, the PCS included notification of arrival and departure of ships and cargo for reporting. In a second phase, the PCS included customs and inspection services. In a third phase, consolidation and specialization of procedures occurred leading to the implementation of automatic processes, in particular automatic billing, with a significant reduction (in some cases elimination) of paper use at the seaport. The fourth phase is associated with the regionalization, with the expansion of the seaport towards the hinterland including information about maritime supply chains that cross the seaport (information related to road and train operators, dry ports, maritime carriers) making possible for all actors to access relevant data. Having access to real-time data synchronization of flows starts to be addressed namely what is called as synchromodal transport (Behdani et al., 2014). Currently a new phase, associated with entrepreneurship related with start-up companies offering and using technology to develop solutions based on artificial intelligence to help decision making at the seaport. This phase is referred as Port Development Companies (PDC) (Langen and Lugt, 2017).

The increase in international freight commerce is stressing the current seaport infrastructure limits. Seaports are being pressured to rethink their 
operations in order to increase the throughput while using the available infrastructure. Seaports are part of international freight networks acting as gateways between foreland and hinterland operations serving both import and export flows. International freight networks are composed of physical locations usually designated as seaports and intermodal terminals, and connections between the physical locations offered by transport providers (Figure 1). The parties present at seaports have as a goal to contribute in some degree to the delivery of cargo on time to the final client. Two main classes of parties are present at freight networks (Rodrigue et al., 2009), i) terminals where cargo is stored and which can support a transport modality switch, and ii) transport operators: which offer transport capacity in different transport modalities between the existing terminals. Although both parties contribute to the overall purpose of the freight network, conflicting operational objectives between them may still arise affecting the whole network performance.

Figure 1

Intermodal freight network [Circles represent terminals and transport connections are indicated by arrows, ST stands for Seaport Terminal; A, B; C and D are hinterland terminals

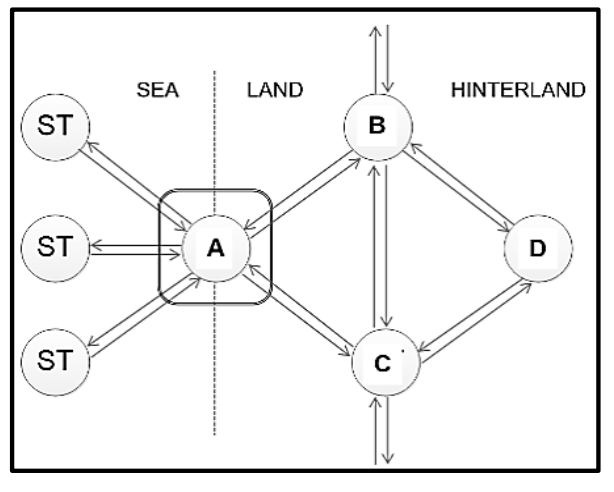

Source: Prepared by authors based on Nabais et al., 2013.

Cargo can be transported over freight networks according to one of the following paradigms (Veenstra et al., 2012; van Riessen et al., 2014): i) merchant haulage in which the shipper or forwarder bears the responsibility of the transport; ii) carrier haulage in which the transport provider organizes the transport; and iii) terminal haulage in which the terminal codetermines the transport. Cargo associated to merchant and carrier haulage waits at the terminal for some transport connection to pick it up towards the final destination. The intermodal terminal at the seaport acts for this type of cargo as a warehouse (Figure 2). For cargo in terminal haulage the terminal has the capability to coassign it to transport connections available at the terminal in accordance to the 
delivery time and destination. Seaports can be seen as a collection of terminals that are physically close sharing resources in particular the transport capacity available at the seaport (Figure 3).

Figure 2

Structural layout of a generic intermodal container terminal

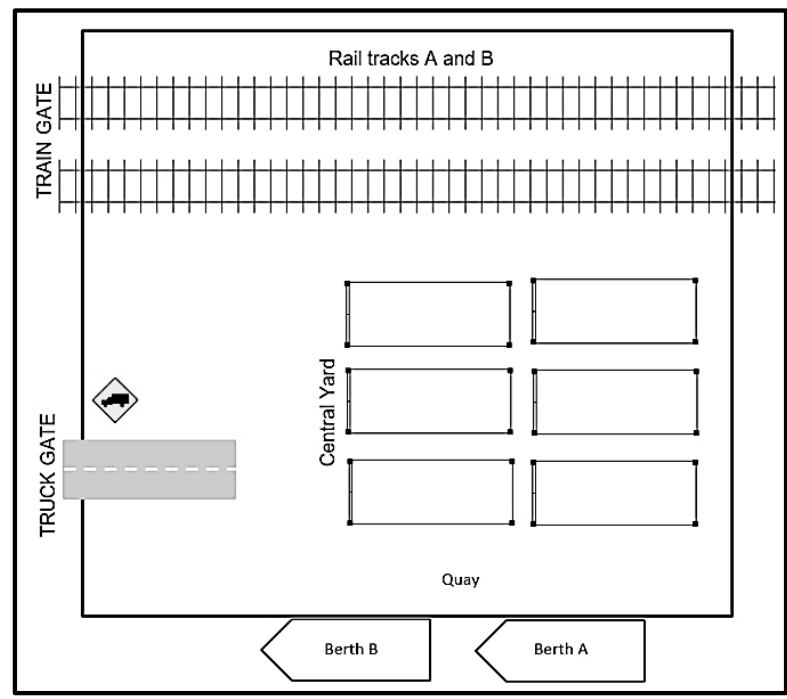

Source: Prepared by authors based on Nabais et al., 2015b.

Figure 3

Seaport A composed of 3 terminals with access to different transport modalities

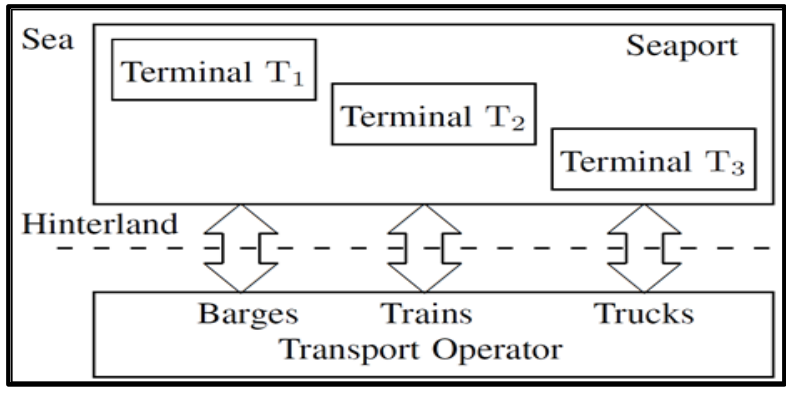

Source: Prepared by authors based on Nabais et al., 2013.

Actors at seaports usually follows a decentralized approach for operations management far from the desired cooperation. That is to say, each actor is trying to solve their operational problems without interacting with the remaining actors at the seaport. This leads to some common situations that halts the seaport efficiency and competitiveness: 
1) increase use of terminals as warehouses instead of places oriented to support load and unloading operations. With a yard full of containers, the terminal will face congestions and operation costs will increase. This is more critical for deep sea terminals;

2) transport providers are called to load cargo at terminals and may face delays if many load/unload operations are held at the same time at the terminal or the terminal is facing a congestion. If many transport providers are called at the seaport congestions may occur.

The necessary information to help wise decisions at the seaport exist but it is distributed over many actors.

Mathematical approaches have been widely applied to transport problem either in the estimation of demands, or in the formulation of multi-objective transport problems aiming to give guidelines for decisions makers (Mármol and Puerto, 1996; Llano, 2004; Gallego et al., 2010). This paper aims to make a contribution on identifying which information is required to support coordination procedures among actors at seaports. This work focus on the interaction amongst terminals and transport providers described in the so-called Modal Split Aware - Cargo Assignment Problem (MSA-CAP) (Nabais et al., 2015a). The MSA-CAP takes the perspective of the intermodal terminal manager. The challenge is to assign the existing cargo to the available transport connections at the terminal such that cargo can reach the final destination on time using only local information. The intermodal terminal is a suitable place to support a transport modal switch in case of necessity to guarantee the cargo delivery on time. Having access to multiple sources of information the intermodal terminal is well suited to assist the cooperation between terminals and transport providers. Freight network information is only partially acknowledged by a few players. With the support of the MSA-CAP it is possible to conceive cooperative methodologies at intermodal terminals for the benefit of either the intermodal terminal itself and the transport provider (SteadieSeifi et al., 2014).

In this paper, freight network performance is evaluated taking the client perspective, which is cargo should be delivered at the right time, on the agreed location in the agreed quantity. Different situations can be addressed using the presented framework (see Figure 4):

1) terminals can be interested in presenting a given Modal Split according to the contract signed with the Port Authority in respect to the concession agreement. In this case, the terminal can start negotiations with transport providers looking for solutions such that cargo can be delivered on time at the final destination following the paradigm of Terminal Haulage; 
2) seaport terminals can cooperate in order to use the available transport at the seaport at maximum capacity reducing the number of vehicles present at the seaport decreasing the risk of congestions halting operations;

3 ) in case delays happen on the transport side and cargo is at risk of not reaching the final destination on time the transport operator can interact with the terminal it will call in order to find a solution (namely a modality switch of cargo) such that cargo can arrive on time at the final destination.

Figure 4

Cargo balance at an intermodal terminal

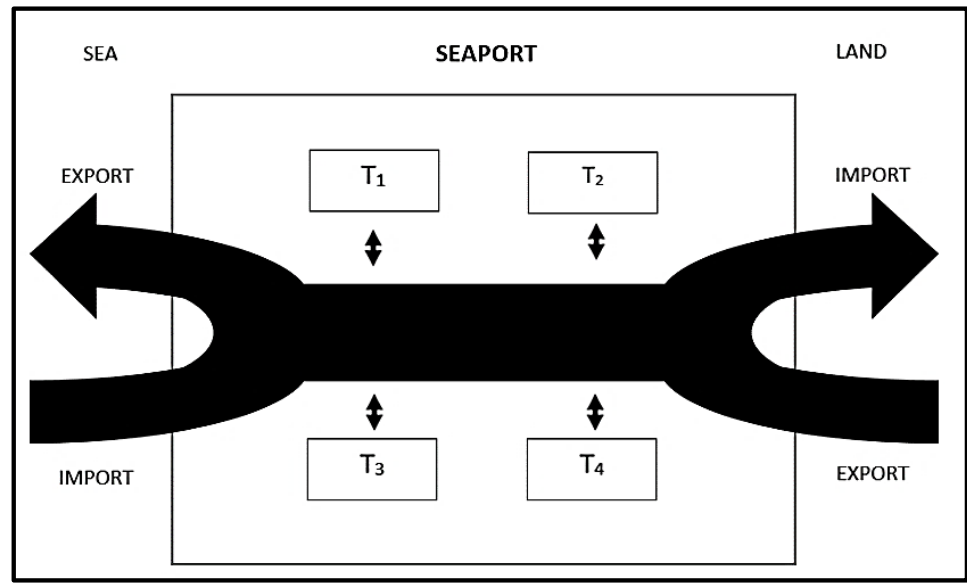

Source: Prepared by authors.

This paper uses the MSA-CAP addressed in Nabais et al. (2015a) enabling it to be applied on real-time decision. A state-space model for cargo evolution over time at intermodal terminals is used. The model sampling time used for simulation can be chosen accordingly to capture the meaningful arrival and departure pattern of transport connections at the terminal, typically measured in hours. Based on this model, a framework for cooperative relations at seaports is presented in three dimensions, i) terminal asks for transport assistance from transport providers, ii) terminals cooperate at the seaport sharing the available transport capacity and iii) transport providers ask for assistance from terminals. Cargo assignment at the hub is addressed using a Model Predictive Control (MPC) approach. MPC has shown successful applications in the process industry (Maciejowski, 2002), and is now gaining increasing attention in fields like supply chains (Maestre et al., 2009), power networks (Geyer et al., 2003), water distribution networks (Negenborn et al., 2009), and freight networks (Li et al., 2014). Using mathematical models, it is possible to make predictions about the future behavior of cargo at intermodal terminals. In freight networks, 
costs can be associated to flows and quantities of stored commodities. The MPC controller can determine which actions have to be chosen in order to obtain the best performance. At each time step the controller first obtains the current state of the system it controls. Then, it formulates an optimization problem, using the desired goals, existing constraints, disturbances and prediction information if available.

This paper is organized as follows. Section 2 presents the state-space model to describe cargo evolution over time at intermodal terminals. Cooperation amongst and between intermodal terminal and transport providers is addressed in Section 3. The performance of the presented approach is illustrated through numerical simulations in Section 4. In Section 5 conclusions are drawn and future research topics are indicated.

\section{MODELLING SEAPORTS}

Cargo evolves over freight networks, namely at seaports, according to its properties (type of cargo, physical location, destination and remaining time until due on destination). This section presents the approach for modeling terminals and a seaport represented as a collection of intermodal terminals that share resources available at the seaport, namely transport capacity.

\subsection{Modelling Approach}

The cargo at the intermodal terminal evolves over time due to cargo arrivals (it is assumed that the terminal accepts all cargo transport providers want to unload there) and cargo departures (which are co-responsibility of the intermodal terminal manager) as depicted in Figure 4. The cargo assignment to transport connections made by the intermodal terminal is based on cargo properties, such as: destination, remaining time until due time, weight, volume, dimension, safety hazard and temperature, amongst others. For modeling purposes, cargo is categorized into two categories:

commodity: is composed of a combination of cargo fixed properties, such as

i) the cargo destination $\left(n_{\mathrm{de}}\right.$ it is the number of available destinations in the freight network), and ii) the cargo type ( $n_{\mathrm{ct}}$ it is the number of different cargo types at the terminal, for example dry and liquid bulk, or container) and iii) other properties according to the convenience of the addressed problem. The total number of commodities present at the terminal is expressed as $n_{\mathrm{fp}}$;

remaining time until due time: this is a time-varying property, used to include time as a distinguishing factor for the same commodity. The remaining time until due time $n_{\mathrm{dt}}$ is the number of time steps until due time of cargo at the destination and is typically measured in hours. This 
property can be used either to capture the due time of cargo at the destination or the expiration date in case of perishable goods. For the sake of readability, from now on this property will be mentioned as due time.

It is important to note that client privacy is protected in this modeling framework. The final destination used as a cargo property is related to the closest (or more convenient) terminal location to the client that is available in the freight network.

\subsection{Modelling Terminals}

The dynamics of an intermodal terminal is captured using a state-space representation. A state-space representation uses a state-space vector to represent the state of the intermodal terminal. The state-space vector gathers all relevant information regarding the existing cargo at the intermodal terminal, and it is updated at each time step $k$ taking into consideration the remaining time until due time, the cargo assigned to connections and the cargo arrivals that occur at that time step.

Therefore, the model can be used to make predictions about cargo evolution over time at the intermodal terminal if data is available. The time step length can be chosen in accordance to the addressed problem. For each commodity $i$ $\left(i=1, \ldots, n_{\mathrm{fp}}\right)$ a state-space vector $\mathbf{x}_{i}$ is defined. This vector is used for creating the terminal state-space vector $\mathbf{x}$ with dimension $n_{\mathrm{x}}$,

$$
\mathbf{x}_{i}(k)=\left[\begin{array}{c}
x^{i 1}(k) \\
\vdots \\
x^{i j}(k) \\
\vdots \\
x^{i n_{\mathrm{dt}_{i}}(k)}
\end{array}\right], \quad \mathbf{x}(k)=\left[\begin{array}{c}
\mathbf{x}_{1}(k) \\
\mathbf{x}_{2}(k) \\
\vdots \\
\mathbf{x}_{n_{\mathrm{fp}}}(k)
\end{array}\right],
$$

Where $x_{i j}(k)$ represents the amount of cargo of commodity $i$ and due time $j$ at time step $\mathrm{k}, n_{\mathrm{dt}_{i}}$ is the number of different due times considered for commodity $i$. The model follows the structural layout of the terminal. This means that the maximum number of transport connections simultaneously at the terminal is known. In the case of the intermodal terminal represented in Figure 2, there are a maximum of 5 transport connections available; two on barge modality, two on train modality and one on truck modality. In this model the control action represents the cargo assigned to each available connection at the terminal at each time step $k$.

For each connection $n_{\mathrm{m}}$ at the intermodal terminal the cargo quantity $\mathbf{u}_{i j}$ that is going to be assigned per commodity $i$ and due time $j$ is determined. The control action associated to connection $m$ is denoted by $u_{\mathrm{m}}$, and all control actions per connection are merged to form the intermodal terminal control action vector $\mathbf{u}$, 


$$
\mathbf{u}_{m}(k)=\left[\begin{array}{c}
u^{11}(k) \\
\vdots \\
u^{i j}(k) \\
\vdots \\
u^{n_{\mathrm{fp}} n_{\mathrm{dt}, \mathrm{fp}}(k)}
\end{array}\right], \quad \mathbf{u}(k)=\left[\begin{array}{c}
\mathbf{u}_{1}(k) \\
\mathbf{u}_{2}(k) \\
\vdots \\
\mathbf{u}_{n_{\mathrm{m}}}(k)
\end{array}\right]
$$

where $n_{\mathrm{m}}$ is the number of available transport connections at the intermodal terminal, and $n_{\mathrm{dt}, \mathrm{fp}}=n_{\mathrm{dt}_{n_{\mathrm{fp}}}}$ is the number of due times for commodity $n_{\mathrm{fp}}$. For each available connection there are $n_{\mathrm{x}}$ decision variables. The control action dimension is $n_{\mathrm{u}}=n_{\mathrm{x}} n_{\mathrm{m}}$.

The cargo arrivals at the terminal are considered as an exogenous input, it is assumed that the terminal accepts all cargo that transport providers want to deliver to the terminal. Therefore, no interference from the terminal is admissible. For each commodity $i\left(i=1, \ldots, n_{\mathrm{fp}}\right)$ a disturbance vector $\mathbf{d}_{i}$ is defined. This vector is used for creating the terminal disturbance vector $\mathbf{d}$,

$$
\mathbf{d}_{i}(k)=\left[\begin{array}{c}
d^{i 1}(k) \\
\vdots \\
d^{i j}(k) \\
\vdots \\
u^{i \mathrm{dt}_{i}(k)}
\end{array}\right], \quad \mathbf{d}(k)=\left[\begin{array}{c}
\mathbf{d}_{1}(k) \\
\mathbf{d}_{2}(k) \\
\vdots \\
\mathbf{d}_{n_{\mathrm{fp}}}(k)
\end{array}\right]
$$

with dimension $n_{\mathrm{x}}$.

The due time of cargo is a critical property to guide the cargo assignment at the intermodal terminal to the available connections. Whenever a cargo can not be assigned to a transport connection such that the due time will be respected, the cargo is categorized as over-due cargo. Overdue cargo $x_{\mathrm{od}, i}$ is defined as the amount of cargo of commodity $i$ that does not reach the final destination on time. The increment on over-due cargo for commodity $i$ at each time step is the difference between the amount of cargo of commodity $i$ with a due time of one time step at the terminal and the amount of cargo of commodity $i$ with a due time of one time step assigned to the transport connections.

Consider the state-space vector for the over-due cargo over time,

$$
\mathbf{x}_{\mathrm{od}}(k)=\left[\begin{array}{c}
x_{\mathrm{od}, 1}(k) \\
\vdots \\
x_{\mathrm{od}, n_{\mathrm{fp}}}(k)
\end{array}\right] .
$$

The augmented state-space vector for the node is represented by $\mathbf{x}_{\mathrm{ag}}(k)$, including the cargo stored at the terminal and the over-due cargo. The statespace model is based on cargo volume conservation and on due time update and is given by 


$$
\begin{array}{ccc}
\mathbf{x}_{\mathrm{ag}}(k+1) & = & \mathbf{A} \mathbf{x}_{\mathrm{ag}}(k)+\mathbf{B}_{\mathrm{u}} \mathbf{u}(k)+\mathbf{B}_{\mathrm{d}} \mathbf{d}(k) \\
\mathbf{y}(k) & = & \mathbf{x}_{\mathrm{ag}}(k) \\
\mathbf{x}_{\mathrm{ag}}(k) & \geq & \mathbf{0}
\end{array}
$$

where $\mathbf{y}$ is the cargo amount per commodity with dimension $n_{\mathrm{y}}=n_{\mathrm{x}}+n_{\mathrm{fp}}$, matrices $\mathbf{A}, \mathbf{B}_{\mathrm{u}}$, and $\mathbf{B}_{\mathrm{d}}$ are the state-space matrices. The state-space representation is composed of the dynamic equation, relating commodities inflow and outflows plus the due time update, and the output equation with access to all states of the model.

\subsection{Modelling Seaports}

The seaport can be seen as a collection of the existing $N$ terminals at the seaport. Each terminal has its own state-space vector $\mathbf{x}_{i}$, cargo arrival pattern $\mathbf{d}_{i}$, and cargo assignment vector $\mathbf{u}_{m}$ (see Figure 5).

Figure 5

Generic seaport represented as a collection of terminals

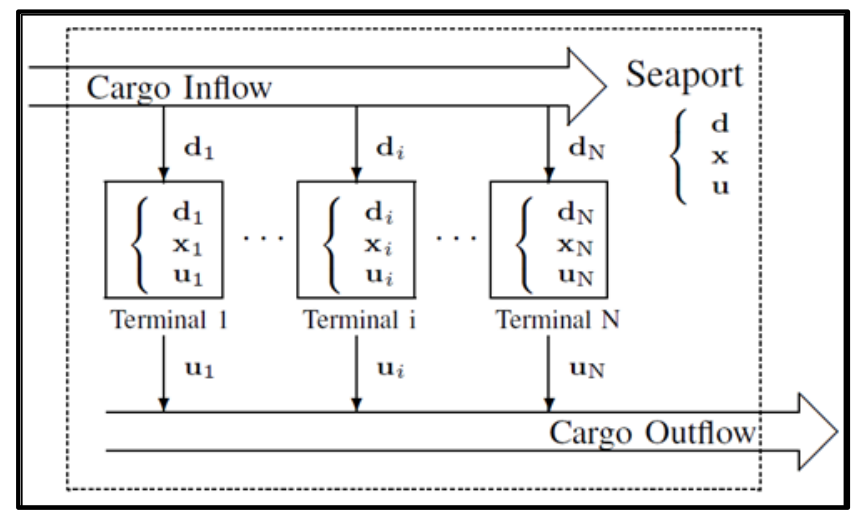

Source: Prepared by authors based on Nabais et al., 2013.

The seaport state-space vector is given by $\mathbf{x}(k)=\sum_{i=1}^{N} \mathbf{P}_{\mathrm{px}, i} \mathbf{x}_{i}(k)$ with length $n_{\mathrm{ct}} n_{\mathrm{de}} n_{\mathrm{dt}}$ where $\mathbf{P}_{\mathrm{px}, i}$ is the projection from the terminal $i$ state-space set $X_{i}$ into the seaport state-space set $X$. The terminal state-space vector has length $n_{\mathrm{x}, i}=n_{\mathrm{de}} n_{\mathrm{dt}}$ if the terminal is dedicated to one cargo type solely. The cargo arrival is considered an exogenous input and disturbs each terminal state. The cargo arrival at the seaport is given by $\mathbf{d}(k)=\sum_{i=1}^{N} \mathbf{P}_{\mathrm{pd}, i} \mathbf{d}_{i}(k)$ with length $n_{\mathrm{ct}} n_{\mathrm{de}} n_{\mathrm{dt}}$ where $\mathbf{P}_{\mathrm{pd}, i}$ is the projection from the terminal $i$ disturbance set $D_{i}$ into the seaport disturbance set $D$. The cargo arrival pattern at each terminal $\mathbf{d}_{i}$ has length $n_{\mathrm{x}, i}$. The control action of each terminal is to assign the quantity of cargo per type, destination and due time to each connection at the seaport. The number of available connections at the seaport at time step $k$ is represented by 
$n_{\mathrm{m}}$. The cargo assignment at the seaport is given by $\mathbf{u}(k)=\sum_{i=1}^{N} \mathbf{P}_{\mathrm{pu}, i} \mathbf{u}_{i}(k)$ with length $n_{\mathrm{u}}(k)=n_{\mathrm{m}} n_{\mathrm{ct}} n_{\mathrm{de}} n_{\mathrm{dt}}$ where $\mathbf{P}_{\mathrm{pu}, i}$ is the projection from the terminal $i$ control action set $U_{i}$ into the seaport control action set $U$. The seaport state $\mathbf{x}$, cargo arrival $\mathbf{d}$, and cargo assignment $\mathbf{u}$ can be separable in terms of the terminals within. The coupling is present in the form of available resources $\Theta$ -transport capacity- at the seaport, so the following relation should hold at each time step $k$,

$$
\mathbf{u}(k)=\sum_{i=1}^{N} \mathbf{P}_{\mathrm{pu}, i} \mathbf{u}_{i}(k) \leq \Theta(k)
$$

Each terminal inside the seaport is modeled based on cargo quantity conservation and due time updates,

$$
\begin{array}{ccc}
\mathbf{x}_{i}(k+1) & = & \mathbf{A}_{i} \mathbf{x}_{i}(k)+\mathbf{B}_{\mathrm{u}, i} \mathbf{u}_{i}(k)+\mathbf{B}_{\mathrm{d}, i} \mathbf{d}_{i}(k) \\
\mathbf{y}_{\mathrm{i}}(k) & = & \mathbf{x}_{i}(k) \\
\mathbf{x}_{i}(k) & \geq & \mathbf{0}
\end{array}
$$

where $\mathbf{y}_{i}$ is the terminal $i$ state, matrices $\mathbf{A}_{i}, \mathbf{B}_{\mathrm{u}, i}, \mathbf{B}_{\mathrm{d}, i}$ are the state-space matrices.

\section{COLLABORATION AT FREIGHT NETWORKS}

Operations management at a terminal is addressed using a MPC approach. At each time step the MPC controller formulates and solves an optimization problem, using collected information about the system it controls (the state, disturbances and predictions if available) and the desired control goal. The optimization problem is formulated taken into consideration the impact of future actions, over a prediction horizon $N_{\mathrm{p}}$ time steps. The solution of the optimization problem is a sequence of control decisions, that according to the desired goal, achieves the best predicted performance. The MPC controller works in a receding horizon fashion, implements only the first component of the optimal sequence (corresponding to the current time step). At the next time step the procedure is repeated leading to a feedback control strategy.

\subsection{Operations Management at the Terminal}

In this paper, operations management at intermodal terminals follows the MSA-CAP previously addressed in Nabais et al. (2015a). Taking the intermodal terminal perspective, the problem to solve can be designated as Transport Modal Split Problem and stated as follows:

Transport Modal Split Target: At each time step $k$, given a known transport capacity per transport modality and destination, how should the existing cargo at the intermodal terminal be assigned to the transport capacity available, taking into account that: 
1. cargo should be delivered at the agreed location and at the agreed time;

2. sustainable transport modalities are preferable options; and

3. the transport modal split is constraint to a strict target window.

The MPC problem for a transport modal split at the intermodal terminal can be stated as (Nabais et al., 2015a):

$$
\begin{gathered}
\min _{\tilde{\mathbf{u}}_{k}} \quad J\left(\tilde{\mathbf{x}}_{\mathrm{ag}, k}, \tilde{\mathbf{u}}_{k}\right) \\
\text { subject to } \\
\mathbf{x}_{\mathrm{ag}}(k+1+l)=\mathbf{A} \mathbf{x}_{\mathrm{ag}}(k+l)+\mathbf{B}_{\mathrm{u}} \mathbf{u}(k+l)+\mathbf{B}_{\mathrm{d}} \mathbf{d}(k+l) \\
\mathbf{y}(k+l)=\mathbf{x}_{\mathrm{ag}}(k+l) \\
\mathbf{x}_{\mathrm{ag}}(k+l) \geq \mathbf{0} \\
\mathbf{u}(k+l) \geq \mathbf{0} \\
\mathbf{P}_{\mathrm{mu}} \mathbf{u}(k+l) \leq \mathbf{u}_{\max }(k+l) \\
\mathbf{P}_{\mathrm{xu}} \mathbf{u}(k+l) \leq \mathbf{x}_{\mathrm{ag}}(k+l) \\
\mathbf{u}(k+l) \leq \mathbf{u}_{\mathrm{adm}}(k+l)
\end{gathered}
$$

where $\mathbf{u}_{\max }$ is the available transport capacity with dimension $n_{\mathrm{m}}, \mathbf{u}_{\mathrm{adm}}$ contains the maximum admissible cargo capacity for each commodity and due time for all transport connections, $\mathbf{P}_{\mathrm{mu}}$ is the time-varying projection matrix from the control action space set into the current connection space set with dimension $n_{\mathrm{u}} n_{m}, \mathbf{P}_{\mathrm{xu}}$ is the time-varying projection from the control action space set into the state space set with dimension $n_{\mathrm{u}} n_{y}$. Constraints introduced in the optimization problem are responsible for imposing the assumptions taken regarding the physical behavior of the system:

- amount of cargo at the terminal is positive;

- only the loading operation of connections is admissible as control action;

- the transport capacity per available connection is limited and known;

- only available cargo at the terminal can be loaded into the transport connections;

- the cargo loaded to each transport connection should respect the connection route and the due time of cargo.

\subsection{Cooperation Between Terminals at Seaports}

For coordination among terminals a control agent is assigned to each terminal which will be responsible for operations management at the terminal following problem (8). The problems each control agent solves are coupled due constraint in transport capacity $\Theta$ available at the seaport. This coupling can be overcome using a control agent dedicated to guide negotiations. The new control agent, designated as a coordinator agent, will update the resource allocation among terminals such that the following relation holds, 


$$
\Theta(k)=\sum_{i=1}^{N} \Theta_{i}(k) .
$$

Using the previous equation in the optimization problem to solve leads to $N$ decoupled cargo assignment problems which are solved by control agents 1 to $N$ using only local information available: the terminal state $\mathbf{x}_{i}$ and the cargo $\mathbf{d}_{i}$. The cooperation problem has been transformed into a resource allocation problem. Control agents share with the coordinator agent the marginal costs associated to the resource allocated, no private information regarding the terminal economical activity is shared. The coordinator agent will execute the resource allocation update, between negotiation steps, based on a switch of resources from the control agent with the lower marginal cost to the one with a higher marginal cost (Johansson and Johansson, 2005). A seaport composed of 3 intermodal container terminals is illustrated in Figure 6.

Figure 6

Cooperation schematics among terminals at a seaport

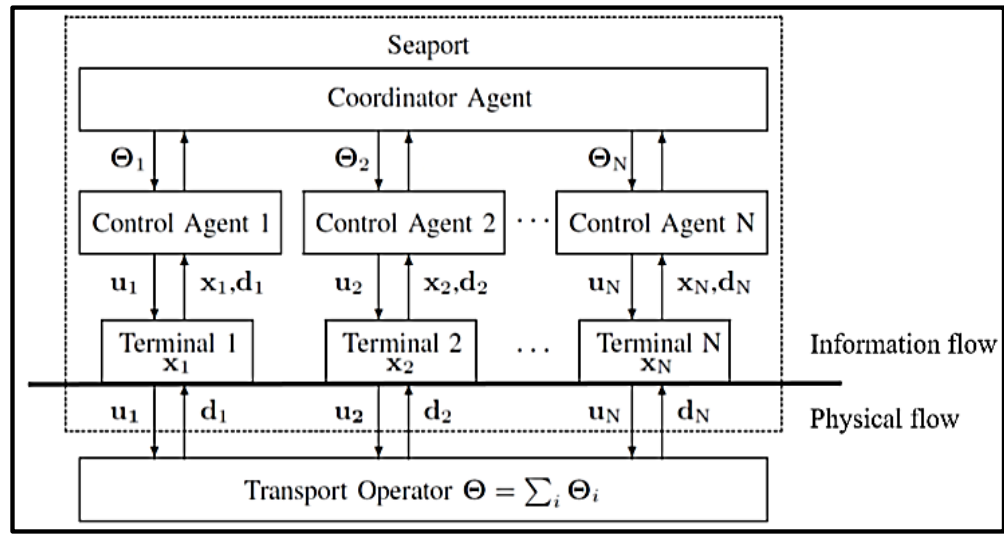

Source: Prepared by authors based on Nabais et al., 2013.

After the initial resource allocation, negotiations between control agents will only start in case of at least one control agent not being capable, over the negotiation horizon $N_{\mathrm{g}}\left(N_{\mathrm{g}} \leq N_{\mathrm{p}}\right)$, to assign all cargo such that it is delivered at the final destination and at the agreed time. Negotiations will continue until there is no over-due cargo over the negotiation horizon for all control agents or no improvement in the solution is made.

\subsection{Cooperation Between Terminals and Transport Providers}

It is assumed that both the terminal and transport providers are willing to cooperate: transport providers can reduce the amount of over-due cargo and the 
terminal may then improve its throughput. The cooperative relation between the terminal and transport providers is based on selective information exchange: first the transport provider $p$ shares the amount of cargo at risk of not being delivered on time $x_{\mathrm{p}, \mathrm{ri}}$ (per commodity and due time), and then the terminal informs the transport provider if a faster connection can be used at the terminal to accommodate the transport delay.

The transport provider whenever arriving at the terminal (or prior to the arrival) announces:

- the available transport capacity per commodity according to the future route;

- the unload operation demands;

- the amount of cargo that is in risk of not being delivered on-time to the final destination.

Having access to updated information about the available transport capacity and cargo at risk, the terminal proceeds with the cooperative procedure, which is composed of two stages:

first stage: the terminal solves the cargo assignment problem (8) for the cargo located at the terminal. From the optimal sequence the terminal determines the amount of over-due cargo using model (5) setting the over-due cargo to zero. The initial value of over-due cargo is used as a performance measure. The terminal starts by accepting all cargo at risk from the transport provider proceeding to the second stage looking for a connection to allocate the cargo at risk that has been temporarily accepted by the terminal;

second stage: the terminal solves the cargo assignment problem (8) including the accepted cargo. The solution found is used to determine the over-due cargo. The amount of over-due cargo is compared with the amount of overdue cargo from the first stage, one of two options will be made: i) if an equal or lower amount of over-due cargo is achieved then the terminal will unload from the transport connection the cargo corresponding to the accepted cargo $\mathbf{x}_{\mathrm{ac}}$ into the terminal, ii) else in case of a higher amount of over-due cargo, the terminal updates the accepted cargo by reducing the accepted amount of cargo. This stage proceeds until over-due cargo is lower or equal to the initial over-due cargo or the accepted cargo $\mathbf{x}_{\mathrm{ac}}$ is smaller than a threshold close to zero.

\section{NUMERICAL EXPERIMENTS}

In this section, numerical experiments will illustrate the potential of the presented framework as a tool to be added to PCS. Three different scenarios will be presented: i) the perspective of the terminal, ii) the perspective of the seaport 
with cooperation among terminals and ii) the perspective of the transport provider.

\subsection{Setup}

Consider the intermodal container terminal A integrated in a freight network composed of 4 intermodal container terminals located in the hinterland as illustrated in Figure 1. Only the hinterland flows are considered, that is to say, destinations A, B, C and D. The terminal offers three transport modalities: barge, train and truck (see Figure 2). It is assumed that there are two berth areas for barges, two rail tracks and finally a truck gate. Without loss of generality, an intermodal terminal with containers as the only type of cargo to be handled is considered, $n_{\mathrm{ct}}=1$. All containers arriving at the terminal are categorized with respect to the final destination, and for each a distinction is made based on the due time. According to the hinterland network $n_{\mathrm{de}}=4$, terminal $\mathrm{A}$ is also an available destination. The number of commodities handled at the terminal is $n_{\mathrm{fp}}=n_{\mathrm{de}}=4$. Concerning the cargo destination, it is assumed that cargo is equally distributed over the 4 possible destinations. So, at the beginning of each time step the cargo assignment will be based on the known information at that time: the intermodal terminal state and the cargo arrival forecast or prediction.

In order to respond to the desired hinterland container flows a network of connections and weekly schedules is created (Nabais et al., 2015b). It is assumed that schedules are a result of agreements between the terminal and transport providers in the freight network, and therefore the terminal has no permission to change it without consent. The focus is on the interactions between the terminal and transport providers offering transport capacity at the terminal, supporting the outgoing cargo. In this case study four different routes are possible: Route $1, R_{1}:(\mathrm{A}, \mathrm{B}, \mathrm{D})$; Route $2, R_{2}:(\mathrm{A}, \mathrm{B}, \mathrm{C}, \mathrm{D})$; Route $3, R_{3}:(\mathrm{A}$, C, D) and Route 4, $R_{4}$ : (A, C, B, D), see Tables $1-2$. For truck modality all destinations are available during opening hours (from 8 a.m. to 24 p.m.). Truck gates are opened for a 16 hours period from Monday to Saturday and the maximum served capacity during the day time is $480 \mathrm{TEU}$. The reachable time per destination for the pair transport modality and route is shown in Table 2 . Destination A is only reachable by truck. The terminal is able to export a maximum of 1430 TEU daily (630 TEU for barge modality, 320 TEU for train modality and 480 TEU for truck modality). The complete model has $n_{\mathrm{x}}=100$ states and $n_{\mathrm{u}}=96 \times 5=488$ cargo assignments to be determined at each time step. 
Table 1

Scheduled connections per barge and train modalities

\begin{tabular}{|c|c|c|c|c|c|}
\hline \multicolumn{3}{|c|}{ Berth A } & \multicolumn{3}{c|}{ Berth B } \\
\hline Departure & Route & Capacity & Departure & Route & Capacity \\
\hline $06: 00$ & $\mathrm{R}_{1}$ & $140 \mathrm{TEU}$ & $03: 00$ & $\mathrm{R}_{1}$ & $70 \mathrm{TEU}$ \\
\hline $15: 00$ & $\mathrm{R}_{2}$ & $140 \mathrm{TEU}$ & $12: 00$ & $\mathrm{R}_{4}$ & $70 \mathrm{TEU}$ \\
\hline $00: 00$ & $\mathrm{R}_{3}$ & $140 \mathrm{TEU}$ & $18: 00$ & $\mathrm{R}_{3}$ & $70 \mathrm{TEU}$ \\
\hline \multicolumn{7}{|c|}{ Rail Track A } & Rail Track B \\
\hline Departure & Route & Capacity & Departure & Route & Capacity \\
\hline $06: 00$ & $\mathrm{R}_{1}$ & 40 TEU & $03: 00$ & $\mathrm{R}_{3}$ & 40 TEU \\
\hline $12: 00$ & $\mathrm{R}_{2}$ & $40 \mathrm{TEU}$ & $09: 00$ & $\mathrm{R}_{4}$ & 40 TEU \\
\hline $18: 00$ & $\mathrm{R}_{3}$ & $40 \mathrm{TEU}$ & $15: 00$ & $\mathrm{R}_{1}$ & $40 \mathrm{TEU}$ \\
\hline $00: 00$ & $\mathrm{R}_{4}$ & $40 \mathrm{TEU}$ & $21: 00$ & $\mathrm{R}_{2}$ & $40 \mathrm{TEU}$ \\
\hline
\end{tabular}

Source: Prepared by authors based on Nabais et al., 2015b.

Table 2

Reachable time steps per destination for the pair route - transport modality

\begin{tabular}{|c|c|c|c|c|c|c|c|c|c|}
\hline \multirow{2}{*}{ Destination } & \multicolumn{5}{|c|}{ Barge } & \multicolumn{5}{|c|}{ Train } & \multirow{2}{*}{ Truck } \\
\cline { 2 - 10 } & $\mathbf{R}_{\mathbf{1}}$ & $\mathbf{R}_{\mathbf{2}}$ & $\mathbf{R}_{\mathbf{3}}$ & $\mathbf{R}_{\mathbf{4}}$ & $\mathbf{R}_{\mathbf{1}}$ & $\mathbf{R}_{\mathbf{2}}$ & $\mathbf{R}_{\mathbf{3}}$ & $\mathbf{R}_{\mathbf{4}}$ & \\
\hline A & & & & & & & & & 1 \\
\hline B & 6 & 6 & & 10 & 4 & 4 & & 6 & 2 \\
\hline C & & 10 & 6 & 6 & & 6 & 4 & 4 & 2 \\
\hline D & 12 & 16 & 12 & 16 & 8 & 10 & 8 & 10 & 4 \\
\hline
\end{tabular}

Source: Prepared by authors based on Nabais et al., 2015b.

\subsection{Transport Modal Split}

For illustration purposes two transport modal split targets are used: $s_{1}$ (45; 20 ; 35 ) of $45 \%$ minimum share for barges, $20 \%$ minimum share for trains and maximum share $35 \%$ for trucks and $\mathrm{s}_{2}(50 ; 25 ; 25)$ of $50 \%$ minimum share for barges, 25\% minimum share for trains and 25\% maximum share for trucks. Each strategy is tested for a prediction horizon of $N_{\mathrm{p}}$ from 1 to 4 time steps. In this experiment the time step is measured in days. For the given configuration the minimum share for truck modality without over-due cargo is precisely $25 \%$. The terminal initial condition was set to create a jam on time step $k=3$. The daily arrival of containers is, in average, 960 TEU. Every 8 days a peak occurs with an arrival of 2200 TEU, with a higher impact on three days due time. The starting time step $k_{s t}$ is considered fixed and equal to the first time step, which means that the transport modal split is being calculated over the whole simulation time. 
Table 3

Cargo assignment per transport modality (in TEU)

\begin{tabular}{|c|c|c|c|c|c|c|c|c|}
\hline & \multicolumn{4}{|c|}{ Modal Split $\mathrm{S}_{1}$ (TEU) } & \multicolumn{4}{c|}{ Modal Split $\mathbf{S}_{\mathbf{2}}(\mathrm{TEU})$} \\
\hline & Barges & Trains & Trucks & Total & Barges & Trains & Trucks & Total \\
\hline$N_{\mathrm{p}}=2$ & 60791 & 26749 & 49359 & 136900 & 64785 & 33417 & 39408 & 137610 \\
\hline$N_{\mathrm{p}}=3$ & 61482 & 27105 & 49443 & 138030 & 67906 & 34604 & 35390 & 137900 \\
\hline$N_{\mathrm{p}}=4$ & 61692 & 27515 & 48841 & 138043 & 68409 & 34491 & 35000 & 137900 \\
\hline
\end{tabular}

Source: Prepared by authors based on Nabais et al., 2015b.

In this case scenario, when increasing the prediction horizon all strategies are able to avoid the existence of over-due cargo due to the capacity of detecting the future occurrence of cargo peaks at the terminal (Table 3-4). With the increase of the prediction horizon there is an effect of anticipating the cargo assignment, which can be stated as pushing containers towards the final destination. The use of a modal split constraint can also increase the pushing of containers as can be seen for $N_{\mathrm{p}}=1$ and $N_{\mathrm{p}}=2$.

Table 4

Cargo assignment per cargo due time (in TEU)

\begin{tabular}{|c|c|c|c|c|c|c|c|c|}
\hline & \multicolumn{4}{|c|}{ Modal Split $\mathbf{S}_{\mathbf{1}}$ (TEU) } & \multicolumn{4}{c|}{ Modal Split $\mathbf{S}_{\mathbf{2}}$ (TEU) } \\
\hline & 1 day & 2 days & $\mathbf{3}$ days & over-due & 1 day & 2 days & 3 days & over-due \\
\hline$N_{\mathrm{p}}=2$ & 81367 & 68497 & 62842 & 750 & 78637 & 53421 & 6552 & 120 \\
\hline$N_{\mathrm{p}}=3$ & 55533 & 46454 & 52080 & 0 & 73045 & 42161 & 22695 & 0 \\
\hline$N_{\mathrm{p}}=4$ & 0 & 23079 & 23126 & 0 & 66189 & 47723 & 23988 & 0 \\
\hline
\end{tabular}

Source: Prepared by authors based on Nabais et al., 2015b.

Figure 7

Transport modal split evolution for $S_{1}$ (left) and $S_{2}$ (right) starting from an initial modal split of $(16 ; 42 ; 42)$ for a total of 14,350 TEU assigned
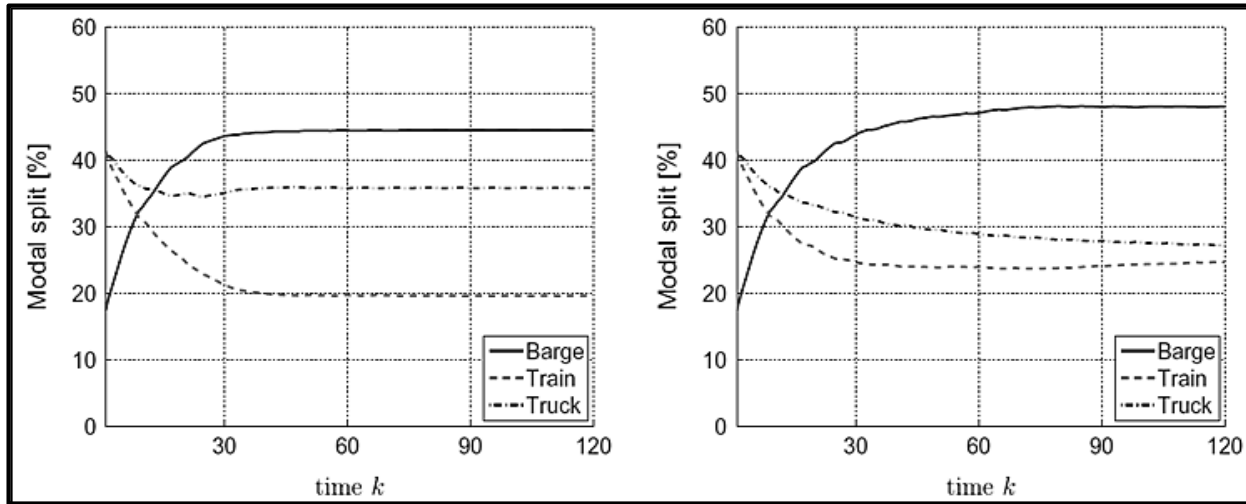

Source: Prepared by authors based on Nabais et al., 2015a. 
The proposed approach is able to achieve a transport modal split target starting from a given Transport Modal Split (see Figure 7). For the same parameters the convergence is affected by the cargo arrival pattern and the topology of the available connections. In this sense, the convergence is slower for target $S_{2}$ due to the challenge of using only truck modality to deliver containers for destination A.

\subsection{Cooperation at Seaports}

For illustration purposes three strategies for terminal cooperation are used:

Centralized $\mathbf{S T}_{1}$ : in this case all terminals provide to the Port Authority all local information about the terminal state $\mathbf{x}_{i}$ and the cargo arrival pattern $\mathbf{d}_{i}$. The seaport acts as a single terminal solving problem (8). Having into account all information available at the seaport this leads to the optimal cargo assignment;

Selfish $\mathbf{S T}_{2}$ : in this case there is no information share between terminals or with the Port Authority. Each terminal negotiates with the transport operator isolated. For comparison issues, we assume that the transport capacity offered by the transport operator is fixed, and divided in equal shares for all terminals. Therefore, to face jams in the transport demand each terminal has to use a longer horizon for planning the cargo assignment;

Altruist $\mathbf{S T}_{3}$ : in this case all terminals are cooperative and they trust on the Port Authority to decide how to share the transport capacity among terminals over the prediction horizon, so $N_{\mathrm{g}}=N_{\mathrm{p}}$. The Port Authority allocates resources among terminals such that the seaport, as a single entity, losses the minimum amount of cargo. Terminals share with the Port Authority the marginal costs related to the use of resources allocated but no information is shared regarding each terminal state or cargo arrival pattern.

Using a centralized strategy is possible to assign all cargo to the transport capacity such that the due time to destination is respected (Table 5). In this scenario, only the altruist strategy is able to perform similarly to the centralized strategy and for $N_{\mathrm{p}} \geq 2$ all cargo is assigned respecting the due time to destination. The selfish strategy only performs well for terminal $T_{2}$ which is the one with less amount of cargo to assign. 
Table 5

Over-due cargo in (TEU) at the seaport using different cooperation strategies among terminals

\begin{tabular}{|c|c|c|c|c|c|c|c|c|c|}
\hline & \multicolumn{3}{|c|}{$N_{\mathrm{p}}=2$} & \multicolumn{3}{c|}{$N_{\mathrm{p}}=3$} & \multicolumn{3}{c|}{$N_{\mathrm{p}}=4$} \\
\hline & $\mathbf{S T}_{1}$ & $\mathbf{S T}_{2}$ & $\mathbf{S T}_{3}$ & $\mathbf{S T}_{1}$ & $\mathbf{S T}_{2}$ & $\mathbf{S T}_{3}$ & $\mathbf{S T}_{1}$ & $\mathbf{S T}_{2}$ & $\mathbf{S T}_{3}$ \\
\hline$T_{1}$ & & 1952 & 450 & & 734 & 0 & & 734 & 0 \\
\hline$T_{2}$ & & 0 & 171 & & 0 & 0 & & 0 & 0 \\
\hline$T_{3}$ & & 1205 & 90 & & 745 & 0 & & 486 & 0 \\
\hline Seaport & 560 & 3157 & 711 & 0 & 1479 & 0 & 0 & 1220 & 0 \\
\hline
\end{tabular}

Source: Prepared by authors based on Nabais et al., 2015b.

Figure 8 - 9 shows the cargo assigned per terminal and negotiation process using the altruist strategy. The number of negotiation steps decreases with the increase of the prediction horizon used, due to more freedom in assigning cargo: 292, 150, and 131 negotiation steps for $N_{\mathrm{p}}=2, N_{\mathrm{p}}=3$, and $N_{\mathrm{p}}=4$, respectively. The terminals altruist behavior is well described in Figure 8 where the cargo loss decreases from $100 \mathrm{TEU}$ to close to $10 \mathrm{TEU}$ at the seaport with $T_{2}$ loosing more cargo at the final negotiation step in benefit of the seaport, that is to say, in benefit of all terminals. For $N_{\mathrm{p}}=2$ the coordinator agent is allocating 32 different types of resources among the three terminals. From Figure 9 it is clear that terminal $T_{3}$ is receiving transport capacity mainly from terminal $T_{2}$. Terminal $T_{2}$ due to the share of transport capacity is forced to use less sustainable transport modalities but with a small share. Connections from 1 to 6 are of barge modality, connection from 7 to 14 are of train modality and the last two connections are of truck modality.

Figure 8

Negotiation steps for $N_{\mathrm{p}}=2$ (left) and negotiation at time step $k=19$ using $N_{\mathrm{p}}=2$ (right)
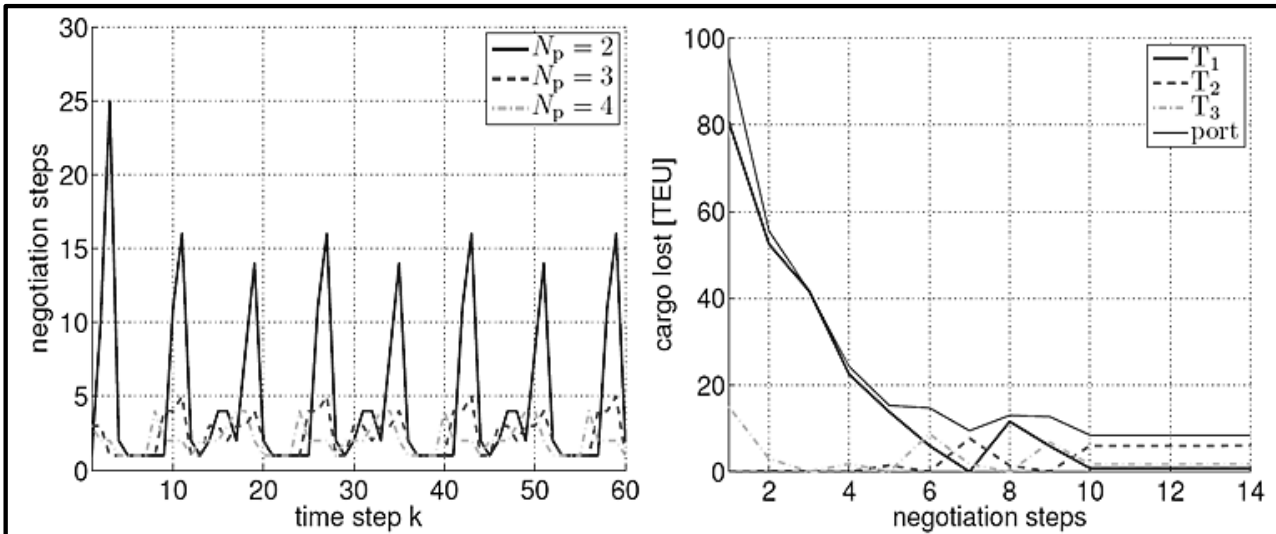

Source: Prepared by authors based on Nabais et al., 2015a. 
Figure 9

Connection splits among terminals for first negotiation step (left) and for last negotiation step (right) $\left(N_{\mathrm{p}}=2, k=19\right)$

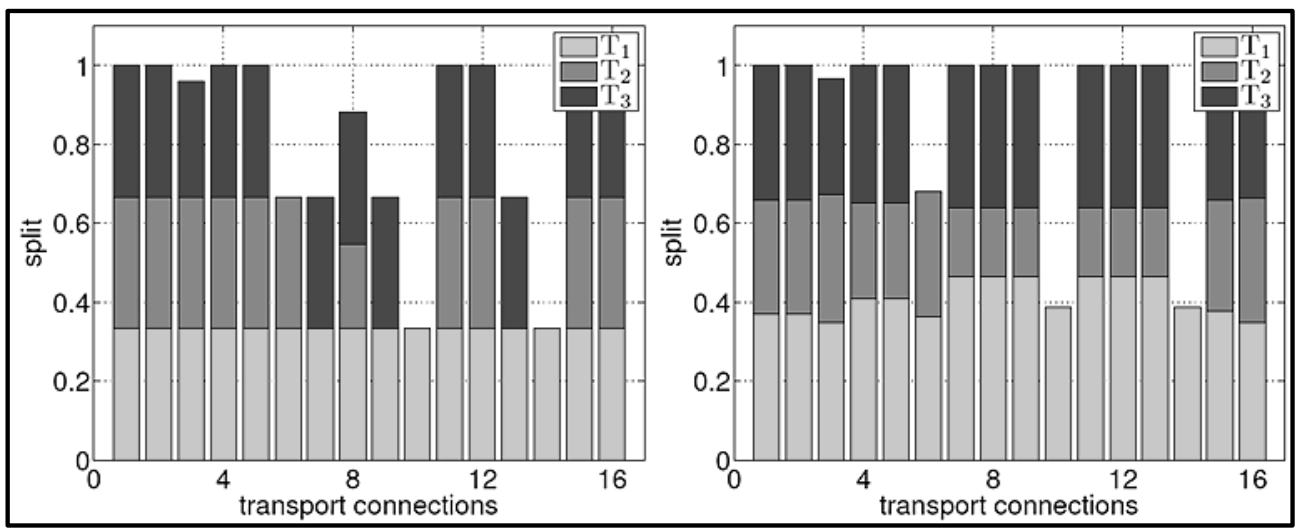

Source: Prepared by authors based on Nabais et al., 2015b.

\subsection{Cooperations Between Terminals and Transport Providers}

For testing the framework, it is defined an arrival pattern of cargo for all the connections that pass by the terminal. In this experiment time step is 3 hours. In order to represent the congestion effect at the end of the week, a peak of cargo arrivals occurs at Friday by a factor of 2. During the weekend road modality is not an option. In respect to the cost function, over-due cargo has a strong penalty, while cargo with a due time from 1 to 4 time steps have a smooth penalty to promote the assignment of cargo, other due times have zero penalty. The truck modality has a stronger penalty than the barge and train modality. The simulation runs for $k=120$ time steps, which corresponds approximately to 2 weeks.

In this case scenario, it is assumed that barge connections arriving at berth A are facing a delay (e.g., due to waiting times at seaport). Cargo being transported by barge A with final destination $\mathrm{D}$, arrive at the terminal with a remaining time until due time of 18 hours, that is to say 6 time steps. Barge A can reach destination $\mathrm{D}$ in 12 or 16 time steps depending on the route used. Destination D is reachable on 4 time steps for truck modality (see Table 2). In this case, without cooperation between the transport provider and the terminal the cargo will not be delivered on time. The delays on barge A are assumed to occur for 4 days (from Monday to Thursday in the first week solely), and an amount of 200 TEU is assumed to be delayed for destination D per connection. At berth A, 12 connections will be affected, and a total of 2400 TEU are at risk of not being delivered on time. The cooperation between terminal and transport provider allowed the transhipment for a faster transport modality and a 
reduction of over-due cargo when considering the terminal and transport provider together (see Table 6).

Table 6

Cooperation details between terminal and transport provider

\begin{tabular}{|c|c|c|c|c|}
\hline$N_{\mathbf{p}}$ & $\begin{array}{c}\text { Total Accepted } \\
\text { Cargo (TEU) }\end{array}$ & $\begin{array}{c}\text { Minimum Accepted Cargo } \\
\text { per Iteration (TEU) }\end{array}$ & $\begin{array}{c}\text { Increase in Used } \\
\text { Transport Capacity (\%) }\end{array}$ & Total \\
\hline 8 & 1092 & 0 & 3.60 & 46 \\
\hline 12 & 1252 & 0 & 6.00 & 41 \\
\hline 16 & 1356 & 7 & 6.62 & 36 \\
\hline 24 & 1374 & 7 & 6.64 & 36 \\
\hline 32 & 1388 & 22 & 6.63 & 35 \\
\hline
\end{tabular}

Source: Prepared by authors based on Nabais et al., 2015b.

Table 7

Over-due cargo, transport capacity used and modal split for cooperation between terminal and transport provider

\begin{tabular}{|c|c|c|c|c|c|c|c|c|c|c|c|c|}
\hline \multirow{2}{*}{$N_{\mathrm{p}}$} & \multicolumn{5}{|c|}{ Over-due cargo (TEU) } & \multicolumn{4}{|c|}{ Used transport capacity (\%) } & \multicolumn{3}{|c|}{ Modal Split (\%) } \\
\hline & A & B & C & D & Total & $A$ & B & C & D & Barge & Train & Truck \\
\hline 8 & 598 & 56 & 255 & 2,237 & 3,146 & 39.1 & 90.1 & 98.4 & 69.1 & 27.38 & 32.46 & 40.16 \\
\hline 12 & 168 & 11 & 49 & 792 & 1,020 & 72.4 & 93.2 & 87.5 & 81.9 & 40.70 & 26.79 & 32.51 \\
\hline 16 & 0.0 & 0.0 & 0.0 & 0.0 & 0.0 & 88.4 & 91.0 & 86.7 & 88.5 & 45.99 & 24.20 & 29.80 \\
\hline 24 & 0.0 & 0.0 & 0.0 & 0.0 & 0.0 & 99.6 & 95.6 & 85.0 & 94.2 & 48.66 & 23.80 & 25.45 \\
\hline 32 & 0.0 & 0.0 & 0.0 & 0.0 & 0.0 & 98.2 & 97.6 & 84.7 & 93.9 & 48.12 & 24.46 & 27.42 \\
\hline
\end{tabular}

Source: Prepared by authors based on Nabais et al., 2015b.

For a prediction horizon of $N_{\mathrm{p}}=32$, a total of 1388 TEU were accepted for transhipment using 35 iterations. The transport provider, with the help of the terminal, reduced the amount of cargo at risk in 57.8\%. Due to the cooperation amongst terminal and transport provider, the terminal faces an increase of overdue cargo for lower prediction horizon, for $N_{\mathrm{p}}=16$ no over-due cargo occurs (see Table 7). For a prediction horizon of 32 time steps a transport modal split of $48 \%$ barges, $25 \%$ trains and $27 \%$ trucks was achieved.

\section{CONCLUSIONS}

This paper presents the Modal Split Aware - Cargo Assignment Problem (MSA-CAP) as a framework capable to guide decisions in order to deliver cargo on time for three different cooperation challenges at seaports. The approach is based on gathering information regarding cargo in particular the remaining time until due time. Having access to the available time to reach the final destination it is possible to support decision making at the PCS. The approach is suitable for real-time decisions supporting the operational. Different perspectives can be taken using this framework, i) the perspective of the terminal looking for a 
transport provider to take the cargo from the terminal such that cargo is delivered on time, ii) cooperation between terminals at the seaport such that the available transport capacity is used to full capacity in order to reduce the risk of congestion at the terminal, and iii) the perspective of the transport provider passing through the seaport that is looking for a solution for the cargo that is at risk of not reaching the final destination on time. The presented framework is used to support the collaboration framework amongst terminal and transport providers. Both parties can take advantage from the interaction, the terminal can increase its throughput and the transport provider can reduce the amount of delayed cargo in a win-win situation. The authors strongly believe that the framework can be successfully integrated in current PCS.

\section{BIBLIOGRAPHY REFERENCES}

BEHDANI, B., FAN, Y., WIEGMANS, B., ZUIDWIJK, R. (2014). "Multimodal schedule design for synchromodal freight transport systems". SSR Electronic Journal.

CARLO, H.J., VIS, I.F.A., ROODBERGEN, K.J. (2014). "Transport operations in container terminals: Literature overview, trends, research directions and classification scheme". European Journal of Operational Research, 236, pp. 1-13.

LANGEN. P.W., LUGT, L. (2017). "Institutional reforms of port authorities in the Netherlands; the establishment of port development companies". Research in Transportation Business \& Management, 2017.

GALLEGO, N., LLANO, C., PÉREZ, J. (2010). "Estimación de los flujos de transporte de mercancías interregionales trimestrales mediante técnicas de interpolación temporal". Estudios de Economía Aplicada, 28(3), pp. 1-38.

GEYER, T., LARSSON, M., MORARI, M. (2003). "Hybrid emergency voltage control in power systems". In: Proceedings of the European Control Conference, Cambridge, UK.

JOHANSSON, B., JOHANSSON, M. (2005). "Primal and Dual Approaches to Distributed Cross-Layer Optimization". 16th IFAC World Congress, Prague, Czech Republic, July.

LI, L., NEGENBORN, R.R., DE SCHUTTER, B. (2014). "A receding horizon approach for container flow assignment". Journal of the Transportation Research Board, 2410, pp. 132-140.

LLANO, C. (2004). "The Interregional Trade in the context of a multirregional input.output model for Spain". Estudios de Economía Aplicada. 22(3), pp. 539-576.

MACIEJOWSKI, J. (2002). Predictive control with constraints. UK: Prentice Hall, Harlow.

MAESTRE, J., DE LA PENA, D.M., CAMACHO, E. (2009). "Distributed MPC: a supply chain case". In: 48th IEEE Conference on Decision and Control and 28th Chinese Control Conference, Shanghai, China. pp. 7099-7104.

MÁRMOL, A.M., PUERTO, J. (1996). "Incorporación de información adicional sonre las preferencias en un problema de transporte multiobjetivo". Estudios de Economía Aplicada, 5, pp. 81-103.

NABAIS, J.L., NEGENBORN, R.R., CARMONA-BENÍTEZ, R., BOTTO. M.A. (2013). "Setting cooperative relations among terminals at seaports using a multi-agent system". 
In 16th IEEE Conference of Intelligent Transportation Systems (ITSC'13), Haia, Holanda, 2013.

NABAIS, J.L., NEGENBORN, R.R., CARMONA BENÍTEZ, R.B., BOTTO, M.A. (2015a). "Achieving transport modal split targets at intermodal freight hubs using a model predictive approach". Transportation Research Part - C, pp. 278-297.

NABAIS, J.L., NEGENBORN, R.R., CARMONA-BENÍTEZ, R., BOTTO. M.A. (2015b). "Cooperative Relations Among Intermodal hubs and Transport Providers at Freight Networks Using an MPC Approach". International Conference on Computational Logistics (ICCL'15), Delft, Holanda.

NEGENBORN, R.R., OVERLOOP, P., KEVICZKY, T., DE SCHUTTER, B. (2009). "Distributed model predictive control of irrigation canals". Networks and Heterogeneous Media, 4, pp. 359-380.

RODRIGUE, J.P., COMTOIS, C., SLACK, B. (2009). The Geography of Transport Systems. Second ed., London: Routledge.

RONDON, J., RAMIS-PUJOL, J. (2006). "Exploring the intricacies if integration with a port community system". BLED 2006 Proceedings, Paper 9. http://aisel.aisnet.org.bled2006/ 9, accessed: 16 may 2014.

STAHLBOCK, R., VOß, S. (2008). "Operations research at container terminals: a literature update". Operations Research Spectrum, 30, pp. 1-52.

STEADIESEIFI, M., DELLAERT, N., NUIJTEN, W., VANWOENSEL, T., RAOUFI, R. (2014). "Multimodal freight transportation planning: A literature review. European". Journal of Operations Research, 233, pp. 1-15.

VAN OOSTERHOUT, M.: ORGANIZATIONS AND FLOWS IN THE NETWORK, IN VAN BAALEN, P. (2008). Zuidwijk, R.; van Nune. J.; Port Inter-Organizational Information Systems. Capabilities to service Global Supply Chains, Foundations and Trends in Technology, Information and Operations Management, vol. 2, n.2-3:93-102, 2.

VAN RIESSEN, B., NEGENBORN, R.R., DEKKER, R., LODEWIJKS, G. (2014). "Impact and relevance of transit disturbances on planning in intermodal container networks using disturbance cost analysis". Maritime Economics \& Logistics, doi: 10.1057/mel.2014.27.

VEENSTRA, A., ZUIDWIJK, R., VAN ASPEREN, E. (2012). "The extended gate concept for container terminals: expanding the notion of dry ports". Maritime Economics \& Logistics, 14, pp. 14-32. 
